\title{
An Autopsy Study of Cases of Deaths Due to Drowning with Special References to Middle Ear Haemorrhage and Spleen Findings
}

\author{
Gitanjali Dass ${ }^{1}$, Vrishty Sharma ${ }^{2}$, Nakul Pandoh ${ }^{3}$ \\ ${ }^{1,2}$ Department of Forensic Science, CTM-IRTE, Faridabad, India \\ ${ }^{3}$ Department of Forensic Medicine and Toxicology, Al-Falah Medical College, Faridabad, India
}

\begin{abstract}
This paper presents an autopsy study of cases of deaths due to drowning with special references to middle ear haemorrhage and spleen findings.
\end{abstract}

Keywords: Autopsy, Drowning, Ear haemorrhage, Spleen Findings, Toxicology, Medicine.

\section{Introduction}

The term death is called the situation of the people in which the life of the people comes to an end. It is called the situation in which the circulation of the blood gets completely stopped. There are many other functions there which do get stops with the proper type of respiration too. There is a form of death which is called as the drowning it is termed as the special type of a death through which the asphyxia death does occur (Alonge et al. 2020). This called as the king of the death through which the air which is of the atmosphere through which the lungs gets the help to respiration is mainly prevented with submersion of the body water and can also be through the other fluid or the medium (Cihan et al. 2018). There are many examples of death are there from the epic and the related stories of the famously based person from the downing. There are also some references related to the Middle ear Hemorrhage and the spleen findings are also analyzed over here.

\section{Research Objectives}

- To determine the age and the sex as well as the seasonal distribution factors of the people who are dying due to the drowning.

- To determine the incidence of the middle ear hemorrhage this is there due to which death occurs and its comparison with the other studies across mainly in the western countries.

- To find the type of death which are occurred

- There is also main importance of the spleen weight and the ratio of the liver weight is also diagnosed in different an organ which is due to the drowning.

- To give a suggestion which is regarding the preventive type of measures this can be taken.

\section{Anatomy of the Clinical System}

\section{A. Respiratory System}

It is called the system in which their network of the organs is there mainly which help the process of breathing to be done. There are some organs which are included which are lings and the blood vessels (da Silva et al. 2018). The main catalyst to make the lungs breathe is the muscles. There is a disease called drowning which occurs mainly because of the respiratory system (Hansen and Thomsen, 2018). There is some vulnerability which do occur in the system which makes the drowning occur.

\section{B. Middle Ear}

This is called the party of the human system in which there is air which contains some space. The communication of the air in this organ can only be done through the nasopharynx. It is mainly done through a tube. There are different types of layers in this organ. The hemorrhage which occurs is also because of the middle ear (Kartha et al. 2019). It mainly results in the blood to be recruited in the eardrum through which the trauma or the hemorrhage which is there can occur.

\section{Spleen}

It is one of the major parts of the human organ and is located in the Hypochondriac region of the human body. It mainly lies between the stomach and the diaphragm and it is also known as the largest gland which is ductless (Khalphallah et al. 2016). The size and weight of the spleen cannot be easily determined. There are variations that come across different levels and the sizes which are mainly there (Le et al. 2016). In the adult, the size can be $12 \mathrm{~cm}$ and the breath up to $7 \mathrm{~cm}$ with a weight of 200 grams

\section{Definition of Drowning}

It is called to be a type of death which occurs to the people and is also called as the asphyxial type of death. In this kind of thing, death is very much sure that it will happen $100 \%$. In this case, the nostril is also there which is submerged and it is a way in which the air is prevented from entering the nostrils

*Corresponding author: gitanjalidass@gmail.com 
(Matsumoto, 2018). According to the definition of the WHO it's considered as a type of a death through which the impairment does occur. There are many types of cases where a person can drown. There are some chemical solutions which can make the person suffer from drowning in which accidentally if a person falls.

\section{Types of Drowning}

There are different types of downing which do exist and it is classified into some special type of the downing which does occur (Milne et al. 2020). Some of the types of downing cases which are there are:

\section{A. Typical Drowning}

1. Fresh Water Drowning: This is a simple type of a downing which occurs in which the water enters into the nostrils and which the respiratory system is affected (Petrović et al. 2019).

2. Salt Water Drowning: It is a type of downing in which the saltwater makes the person vomit and gets affected due to the salt and the water both.

\section{B. Atypical Drowning}

There are also some drowning cases which are very typical types in which some of the types of the drowning cases are dry drowning and the submersion cases as well as the syndrome of the drowning which does occur (Tse, 2018).

\section{Stages of the Drowning}

There are some stages that are there of the drowning cases which are been autopsied and there are some stages through which the human suffers in this case of the death which are as follows:

1. The first stage which is called as the stage of the surprise

2. This is called the second stage in which the respiratory arrest does occur

3. The third step in which the deep respiration is very much needed

4. The last stage of the respiratory based arrest

5. The stage in which there is terminal gasp is there.

\section{Pathophysiology}

\section{A. Sequential events in drowning}

It has been observed that there are certain stages of drowning that occur in chain system for a victim to die. In the words of Roy and Srinivasan, (2018), detection of drowning methods is essential for safety of swimmers. The first stage is observed to be breath-holding that forces a person to attempt for a vertical uprising from under a water body. It has been analyzed that a mammalian diving reflex is observed while getting drowned. However, under this reflex, drowning person shows much distress and difficulty in breathing. It consists of three effects namely bradycardia, peripheral vasoconstriction and blood shift. In the first effect, both parasympathetic and sympathetic tone of the heart increase bradycardia resulting in slowing down of the heart beat by $50 \%$ (Vincenzi, 2018). In the second effect, the flow of blood increases to important parts of the body, specially the brain of the victim. The third effect result in increased blood flow to the thoracic region to address the collapsing of lungs due to lack of inhaling. According to Bierens et al. (2016), both immersion and submersion relate to the cutting of upper air on or under the water surface. Hence, the second stage is known as the involuntary inspiration due to deprivation of oxygen. The inverse relationship between breathing reflex and amount of oxygen and carbon dioxide makes up this stage. In order to save more oxygen in the blood, drowning victim tries to hold his or her breath creating more panic and haphazard movements. This leads to the third stage known as the gasping stage that occurs $\mathrm{s}$ the limited oxygen is burned out leading to inhalation of air and swallowing of water resulting in laryngospasm.

\section{B. Stages of drowning}

There are five stages of drowning that are important for interpreting an autopsy report of a drowned victim. Scientific approach is important for delving deep into the drowning concept for precise understanding (Ayub et al. 2020). The first stage is known as the surprise stage that makes a victim cautious about his or her drowning. The person is observed to be in a vertical position without movements of the legs. The second stage is involuntary holding of breath that forces a person to gasp for breath as water enters the epiglottis and clog the airway. The third stage is the state of unconsciousness due to fall in oxygen level below the static line. Hypoxic convulsions follow as the lips and beds of fingernails turn blue due to lack of oxygen in the brain leading to clinical death depicting no circulation of blood and breathing.

\section{Dry drowning}

The term itself depicts the type of death that occurs to a person getting drowned. In the words of Dowd, (2017), there are certain misconceptions regarding dry drowning cases across the globe. In this type of drowning cases, autopsy reports reveal that the lungs of the victim remain dry as water is blocked by the spasm in the larynx. As a result, the victim suffers from asphyxia due to cut off of oxygen. It has been observed in autopsy reports that the vocal cords of the victim remains clogged resulting in lack of oxygen in the blood. Drowning is a preventable accident but common across the globe (HAWKINS, 2018). It is important to break the myth regarding dry drowning. Autopsy reports have clarified that nearly $15 \%$ of deaths from dry drowning showed no fluid aspiration in the lungs. A drying up of lungs is followed by sudden cardiac arrest of the victim.

\section{Conclusion}

It can be concluded that the features of the drowning and the references which are related to the middle ear and the spleen finding are analyzed over here. The above analysis which is done will easily help to make the autopsy to be done in an efficient manner. There are several methods are there which are also discussed over here in the related aspect are also illustrated over here. Thus it can be also concluded that the respiratory 
arrest is the cause of the drowning and leading to deaths.

\section{References}

[1] Alonge, O., Bishai, D., Wadhwaniya, S., Agrawal, P., Rahman, A., Dewan Hoque, E.M., Baset, K.U., Salam, S.S., Bhuiyan, A.A., Islam, M.I. and Talab, A., 2020. Large-scale evaluation of interventions designed to reduce childhood Drownings in rural Bangladesh: a before and after cohort study. Injury epidemiology, 7, pp.1-12.

[2] Ayub, S., Gunawan, G., Ramdani, A. and Afifah, G., 2020, February. Student Oriented Learning in Floating and Drowning Concept. In Journal of Physics: Conference Series (Vol. 1471, No. 1, p. 012062). IOP Publishing.

[3] Bierens, J.J., Lunetta, P., Tipton, M. and Warner, D.S., 2016. Physiology of drowning: a review. Physiology.1-20

[4] Cihan, E., Hesdorffer, D.C., Brandsoy, M., Li, L., Fowler, D.R., Graham, J.K., Donner, E.J., Devinsky, O. and Friedman, D., 2018. Dead in the water: Epilepsy-related drowning or sudden unexpected death in epilepsy?. Epilepsia, 59(10), pp.1966-1972.

[5] da Silva, L.S., Ribeiro, G.E., Montovani, J.C. and da Silva, D.P.C., 2018 The effect of peri-intraventricular hemorrhage on the auditory pathway of infants. International journal of pediatric otorhinolaryngology, 112, pp.24-26.

[6] Dhande, B., Kothawade, Y., Kulkarni, A. and Askhedkar, A., 2018. Comprehensive Survey of Drowning Detection and Rescue Techniques. International Research Journal of Engineering and Technology (IRJET), 5 , p. 2028.

[7] Dowd, M.D., 2017. Dry drowning: myths and misconceptions. Pediatric annals, 46(10), pp. 354-357.

[8] Hansen, I.B. and Thomsen, A.H., 2018. Circumstances and autopsy findings in drownings, Department of Forensic Medicine, Aarhus University, 2006-2015. Scandinavian journal of forensic science, 24(1), pp.1-6.

[9] Hawkins, S.C., 2018. 'Dry drowning'and other myths. Cleveland Clinic Journal of Medicine, 85(7), p. 529.

[10] Hussein, H.N., Hashim, N.G. and Ahmed, N.M., 2020. Medico-legal Significance of Diatoms Detection in Different Organs of Drowning Victims. Indian Journal of Forensic Medicine \& Toxicology, 14(2), pp.1567-1573.

[11] Kartha, M., Ramakrishnan, U.K., Balachandran, A. and Umadethan, B., 2019. The Presence of Diatoms in Liver Tissue in Non-Drowning Cases: An Autopsy based Study. Indian Journal of Forensic Medicine \& Toxicology, 13(1), pp.25-31.

[12] Khalphallah, A., Elsayed, H.K., Elmeligy, E.N.A.S. and El-Hawari, S.F., 2016. The ultrasonographic findings of the gastrointestinal tract and spleen in healthy Egyptian Buffaloes (Bubalus bubalis). Assiut Vet Med J, 62(148), pp.9-47.
[13] Kumar, N., Mangare, V., Kandpal, N. and Bajpei, A., 2019. Autopsy based profile of drowning cases at a tertiary care centre near a hilly river. Indian Journal of Forensic and Community Medicine, 6(1), pp.28-32.

[14] Le, D., Schierloh, U., Van Nieuwenhuyse, J.P. and Nchimi, A., 2016. Magnetic resonance imaging findings of Intrapancreatic accessory spleen. Journal of the Belgian Society of Radiology, 100(1).

[15] Liu, H., Wen, B. and Frej, M.B.H., 2019, August. A Novel Method for Recognition, Localization, and Alarming to Prevent Swimmers from Drowning. In 2019 IEEE Cloud Summit (pp. 65-71). IEEE.

[16] Maity, S., Chowdhuri, S., Das, S. and Das, S.K., 2020. A Demographic Study on Cases of Drowning with Special Reference to Histopathological Changes of Lung and Other Tissues in a Tertiary Centre. Indian Journal of Forensic Medicine \& Toxicology, 14(3), pp.63-69.

[17] Matsumoto, K., Kato, H. and Okada, H., 2018. Epidermoid cyst in an intrapancreatic accessory spleen diagnosed by typical radiographic images and endoscopic ultrasound fine-needle aspiration findings with contrast agent. Clinical Gastroenterology and Hepatology, 16(2), pp. 1314.

[18] Milne, E., Nuttall, T., Marioni-Henry, K., Piccinelli, C., Schwarz, T., Azar, A., Harris, J., Duncan, J. and Cheeseman, M., 2020. Cytological and microbiological characteristics of middle ear effusions in brachycephalic dogs. Journal of Veterinary Internal Medicine.

[19] Pal, S.K., Sharma, A., Sehgal, A. and Rana, A., 2017. Diagnosing Death with Diatoms: A Retrospective Study of Forensic Cases in Himachal Pradesh, India. International Journal of Medical Toxicology and Forensic Medicine, 7(2 (Spring)), pp. 124-137.

[20] Petrović, F., Stojanov, D., Živković, N., Zdravković, J., Petrović, M., Milisavljević, D. and Radovanović, Z., 2019. Glomus tympanicum paraganglioma in a 63-year-old male: A rare entity in the middle ear: A case report. Acta medica Medianae, 58(3), pp. 97-101.

[21] Roy, A. and Srinivasan, K., 2018, December. A novel drowning detection method for safety of Swimmers. In 2018 20th National Power Systems Conference (NPSC) (pp. 1-6). IEEE.

[22] Singh, R. and Zolawmsangi, O.P., 2016. A preliminary study on the Diatom flora of various drowning sites in Mizoram rivers. Anil Aggrawal's Internet Journal of Forensic Medicine and Toxicology, 17(2).1-17.

[23] Tse, R., Garland, J., Kesha, K., Morrow, P., Lam, L., Elstub, H., Cala, A., Spark, A., Palmiere, C. and Stables, S., 2018. The potential diagnostic accuracy of autopsy lung weights, lung-heart ratio, and lung-body ratio in drowning deaths. The American journal of forensic medicine and pathology, 39(3), pp. 223-228.

[24] Uppu, R.S., Rao, B.A. and Rajesh, B., 2020. An Autopsy Study of Drowning Deaths in and around Visakhapatnam. Indian Journal of Forensic Medicine \& Toxicology, 14(1), pp. 23-27.

[25] Vincenzi, F.F., 2018. Fatal drowning associated with QT prolongation caused by alcohol, some drugs, and congenital long QT syndrome: the role of the diving reflex. EC Pharmacol. Toxicol, 6(7), pp. 622-633. 